\title{
Soluble CD14 Enhances the Response of Periodontal Ligament Stem Cells to Toll-Like Receptor 2 Agonists
}

\author{
Christian Behm, Alice Blufstein, Johannes Gahn, Nazanin Noroozkhan, Andreas Moritz, \\ Xiaohui Rausch-Fan, and Oleh Andrukhov iD
}

\author{
Division of Conservative Dentistry and Periodontology, University Clinic of Dentistry, Medical University of Vienna, \\ Vienna 1090, Austria \\ Correspondence should be addressed to Oleh Andrukhov; oleh.andrukhov@meduniwien.ac.at
}

Received 6 December 2018; Revised 17 February 2019; Accepted 13 March 2019; Published 23 April 2019

Guest Editor: Denisse Bravo

Copyright ( 2019 Christian Behm et al. This is an open access article distributed under the Creative Commons Attribution License, which permits unrestricted use, distribution, and reproduction in any medium, provided the original work is properly cited.

\begin{abstract}
Human periodontal ligament stem cells (hPDLSCs) do not express membrane-bound CD14, and their responsiveness to bacterial lipopolysaccharide (LPS) is drastically enhanced by soluble CD14 (sCD14), which is due to the facilitation of the interaction between LPS and Toll-like receptor- (TLR-) 4. Several studies also show that sCD14 enhances the responsiveness of different immune cells to TLR-2, but such effect in hPDLSCs has not been studied so far. In the present study, we investigated for the first time the potential effect of sCD14 on the hPDLSC response to two different TLR-2 agonists, in vitro. Primary hPDLSCs were stimulated with synthetic lipopeptide Pam3CSK4 or lipoteichoic acid (LTA) in concentrations $1-1000 \mathrm{ng} / \mathrm{ml} \mathrm{in}$ the presence $/ a b s e n c e$ of sCD14 $(250 \mathrm{ng} / \mathrm{ml})$. Additionally, the effect of different sCD14 concentrations $(2.5-250 \mathrm{ng} / \mathrm{ml})$ on the TLR-2 response was determined in Pam3CSK4- or LTA-triggered hPDLSCs. The resulting expression of interleukin- (IL-) 6, chemokine C-X-C motif ligand 8 (CXCL8), and chemokine $\mathrm{C}-\mathrm{C}$ motif ligand 2 (CCL2) was measured by qPCR and ELISA. The production of IL-6, CXCL8, and CCL2 was gradually increased by both TLR-2 agonists and was significantly enhanced by sCD14. The response of hPDLSCs to low and submaximal concentrations of TLR-2 agonists (1-100 ng/ml) was most effectively enhanced by sCD14. The effect of sCD14 on TLR-2 response in hPDLSCs was concentration-dependent and was already detectable at low sCD14 levels. Our data showed that exogenous sCD14 significantly enhanced the responsiveness of hPDLSCs to TLR-2 agonists and enabled the detection of their small amounts. This effect was already detectable at low sCD14 levels, which are comparable to those in saliva and gingival crevicular fluid. Changes in the local sCD14 level may be considered as a crucial factor influencing the susceptibility of hPDLSCs to different pathogens and thus may contribute to the progression of periodontitis.
\end{abstract}

\section{Introduction}

Mesenchymal stem cells (MSCs) are multipotent progenitor cells, exhibiting self-renewal potential and an ability to differentiate in vitro into multiple cell types [1]. MSCs reside in various dental tissues [2-4], including the periodontal ligament [5]. Human periodontal ligament stem cells (hPDLSCs) are a heterogenous population of fibroblast-like cells [6], which fulfils the minimal criteria for MSCs such as the expression of characteristic surface markers and the multilineage differentiation potential $[6,7]$. Similar to other MSCs, hPDLSCs possess immunomodulatory ability and modulate the activity of immune cells by either paracrine mechanisms or direct cell-to-cell contact. hPDLSCs are involved in regulating the processes implicated in periodontal tissue homeostasis, regeneration, and periodontal disease progression $[6,8,9]$.

Periodontitis is an inflammatory, multifactorial disease, leading to periodontal tissue destruction and may result in tooth loss in severe cases $[10,11]$. It is associated with an impairment of host-microbial homeostasis, leading to an inappropriate, overwhelming immune response [12], and is affected by several risk factors including genetic predisposition [13] and smoking habits [14]. The Gram-negative bacterium Porphyromonas gingivalis is most often associated with periodontitis $[15,16]$ and is currently considered as a 
keystone pathogen [17]. P. gingivalis and its virulence factors, like lipopolysaccharide (LPS) $[18,19]$ and various lipoproteins $[20,21]$, induce an inflammatory response in hPDLSCs and influence their immunomodulatory potential.

Bacterial components are recognized by TLRs, a family of pattern recognition receptors of the host cells [21-26]. The activation of TLRs in hPDLSCs results in the production of different inflammatory mediators and is assumed to regulate their immunomodulatory ability [27]. hPDLSCs express different types of TLRs including TLR-2 and TLR-4, which sense lipoproteins and bacterial LPS, respectively [28-30]. Previous studies show that activation of hPDLSCs by $P$. gingivalis LPS leads to the secretion of several potent proinflammatory mediators, like interleukin- (IL-) $1 \beta$, IL-6, chemokine C-X-X motif ligand 8 (CXCL8), and chemokine C-C motif ligand 2 (CCL2) $[18,19]$. In contrast to specialized immune cells, hPDLSCs exhibit a very low reactivity to $P$. gingivalis LPS in concentrations up to $1 \mu \mathrm{g} / \mathrm{ml}$, reaching a strong activation with only a quite high $P$. gingivalis LPS concentration $(10 \mu \mathrm{g} / \mathrm{ml})$ [18]. The low sensitivity of hPDLSCs to $P$. gingivalis LPS is explained by the lack of membrane-bound CD14 on the hPDLSC surface $[9,19]$, an important coreceptor of TLR-4 [31,32]. Our previous study shows that the soluble form of CD14 (sCD14) significantly enhances the response of hPDLSCs to $P$. gingivalis and Escherichia coli LPS and allows sensing even low LPS levels in the range of $\mathrm{ng} / \mathrm{ml}[19,33]$.

Several studies indicate an association between periodontitis progression and TLR-2 (reviewed in [34]). Lipoproteins of different bacteria, including $P$. gingivalis, are the main ligands of TLR-2 [20, 21, 35]. A study of Morandini et al. shows that lipoprotein-induced expression of IL-6 and CXCL8 is significantly decreased in TLR-2-silenced periodontal ligament fibroblasts [21]. A recent study of our group shows that the synthetic TLR-2 agonist Pam3CSK4, a triacylated lipoprotein, induces a significantly higher inflammatory response in hPDLSCs than bacterial LPS [19].

Previous studies on distinct immune cells suggest that sCD14 might enhance the TLR-2 activation in the presence of an appropriate agonist [36-39]. Ranoa et al. demonstrates an involvement of sCD14 in the interaction of TLR-2 with synthetic triacylated lipopeptides, making cells susceptible for lipopeptides even on the nanogram range [38]. Further, Nakata et al. shows that CD14 directly binds triacylated lipopeptides, without binding TLR-2 [36]. Additionally, other studies also show a CD14-dependent induction of the cytokine synthesis in $\mathrm{T}$ cells and monocytes after stimulation with TLR-2 agonist lipoteichoic acid (LTA) [37, 40]. To the best of our knowledge, the potential of sCD14 to modulate the activation of TLR-2 in hPDLSCs is not known to date. Therefore, in the present study, we investigated the effect of sCD14 on the response of hPDLSCs to TLR-2 agonists. Particularly, we measured the expression of IL-6, CXCL8, and CCL2 in hPDLSCs upon stimulation with different concentrations of the synthetic triacylated lipoprotein Pam3CSK4 or LTA in the presence/absence of a single SCD14 concentration. Further, we tested the dependency of the hPDLSC response to a submaximal response to TLR-2 agonists on different $\mathrm{sCD} 14$ concentrations.

\section{Material and Methods}

2.1. Cell Culture. Third molars from five different periodontally healthy patients were extracted due to orthodontic reasons and used to isolate primary hPDLSCs, as described in our previous study [19]. All patients were informed and gave their written consent before the surgical procedure. The study protocol was approved by the Ethics Committee of the Medical University of Vienna. All procedures were performed according to the "Good Scientific Practice" guidelines of the Medical University of Vienna and the Declaration of Helsinki. Primary hPDLSCs were cultured under humidified conditions in Dulbecco's modified Eagle's medium (DMEM, Sigma-Aldrich, St. Louis, USA), supplemented with $10 \%$ fetal bovine serum (FBS, Gibco, Carlsbad, USA), $1 \%$ penicillin, and streptomycin (P/S, Gibco, Carlsbad, USA). Cells between the $3 \mathrm{rd}$ and 7 th culture passages were used for the experiments. Cell surface marker expression of mesenchymal stem cells (CD29, CD90, CD105, and CD146) and of hematopoietic cells (CD14, CD31, CD34, and CD45) was analysed to verify minimal MSC criteria in isolated hPDLSCs [19].

2.2. Stimulation Protocol. Primary hPDLSCs were seeded in 24-well plates at a density of $5 \times 10^{4}$ cells per well, in $0.5 \mathrm{ml}$ DMEM, supplemented with $1 \% \mathrm{P} / \mathrm{S}$ and $10 \% \mathrm{FBS}$. In the first series of experiments, the effect of sCD14 in a constant concentration of $250 \mathrm{ng} / \mathrm{ml}$ on the response of hPDLSCs to different concentrations of TLR-2 agonists was investigated. The sCD14 concentration was chosen due to our experience from a previous study [19]. Cells were stimulated with either TLR-2/1 agonist Pam3CSK4 (InvivoGen, San Diego, USA) or TLR-2 agonist lipoteichoic acid (LTA, InvivoGen, San Diego, USA) 24 hours after seeding. Stimulation was done with different concentrations $(1,10,100$, and $1000 \mathrm{ng} / \mathrm{ml})$ of TLR-2 agonists in the presence/absence of exogenous sCD14 (Sigma-Aldrich, St. Louis, USA). In the second series of experiments, the impact of different sCD14 concentrations on the hPDLSC response to constant concentrations of TLR2 agonists was examined. In these experiments, the cells were treated with submaximal concentrations $(10 \mathrm{ng} / \mathrm{ml})$ of either Pam3CSK 4 or LTA in the presence of SCD14 at concentrations $2.5,10,25,100$, and $250 \mathrm{ng} / \mathrm{ml}$. All stimulations were performed in duplicates and in FBS-free DMEM, supplemented with $1 \% \mathrm{P} / \mathrm{S}$. After 24 hours of stimulation, IL-6, CXCL8, and CCL2 gene expression levels were measured by quantitative polymerase chain reaction (qPCR), and the levels of corresponding proteins in the conditioned media were determined using the enzyme-linked immunosorbent assay (ELISA).

2.3. Quantitative PCR. The TaqMan Gene Expression Cellsto-CT kit (Applied Biosystems, Foster City, USA) was used for cell lysis, mRNA extraction, reverse transcription into cDNA, and qPCR according to the manufacturer's protocol. Reverse transcription was conducted on the Primus 96 advanced thermocycler (PeqLab/VWR, Darmstadt, Germany) using the following settings: $37^{\circ} \mathrm{C}$ for 1 hour and $95^{\circ} \mathrm{C}$ for 5 minutes for enzyme deactivation followed 
by $4^{\circ} \mathrm{C}$. $\mathrm{qPCR}$ was performed using the ABI StepOnePlus device (Applied Biosystems, Foster City, USA) with the following thermocycler settings: 10 minutes at $1 \times 95^{\circ} \mathrm{C}$ followed by $50 \times 15$ seconds at $95^{\circ} \mathrm{C}$ and 1 minute at $60^{\circ} \mathrm{C}$. For amplifying the target genes, the following TaqMan Gene Expression Assays (Applied Biosystems, Foster City, USA) were used: IL-6, Hs00985639_m1; CXCL8, Hs00174103_m1; CCL2, Hs00234140_m1; and GAPDH Hs99999905. qPCR was performed in paired reactions, followed by specifying the $\mathrm{Ct}$ value for each sample. Gene expression levels were quantified using the $2^{-\Delta \Delta C t}$ method by the formula

$$
\Delta \Delta \mathrm{Ct}=\left(\mathrm{Ct}^{\text {target }}-\mathrm{Ct}^{\mathrm{GAPDH}}\right)_{\text {sample }}-\left(\mathrm{Ct}^{\text {target }}-\mathrm{Ct}^{\mathrm{GAPDH}}\right)_{\text {control }} \text {. }
$$

The $n$-fold expression of the target genes compared to the corresponding untreated control was determined. GAPDH served as endogenous reference.

2.4. Enzyme-Linked Immunosorbent Assay. For determining IL-6, CXCL8, and CCL2 protein levels in the conditioned media, ELISA Ready-Set-Go! Kits (eBioscience, Waltham, USA) were used, according to the manufacturer's protocol. ELISAs were performed in duplicates, followed by measuring optical density at $450 \mathrm{~nm}$. Measured absorbance values were plotted against the corresponding standard curves, determining the appropriate protein concentrations.

2.5. Statistical Analysis. The statistical program SPSS 24.0 (IBM, Armonk, USA) was used for all statistical analysis. The Friedman test followed by the Wilcoxon test for pairwise comparison was used. Differences with $p$ values $<0.05$ were considered as statistically significant.

\section{Results}

3.1. Effect of sCD14 on the hPDLSC Response to TLR-2 Agonist Pam3CSK4. Gene and protein expression levels of IL-6, CXCL8, and CCL2 in primary hPDLSCs, stimulated with different Pam3CSK4 concentrations in the presence/ absence of sCD14 $(250 \mathrm{ng} / \mathrm{ml})$, are shown in Figure 1. In the absence of sCD14, Pam3CSK4 induced a concentrationdependent increase in IL-6, CXCL8, and CCL2 gene expression levels. The highest response was observed at $1000 \mathrm{ng} / \mathrm{ml}$ Pam3CSK4. Stimulation with 10 to $1000 \mathrm{ng} / \mathrm{ml}$ Pam3CSK4 led to a significant increase in IL-6, CXCL8, and CCL2 gene expressions. Exogenous sCD14 significantly enhanced the expressions of IL-6, CXCL8, and CCL2 at submaximal Pam3CSK4 concentrations (1-100 ng/ml). The response to the highest Pam3CSK4 concentration (1000 ng/ml) was not significantly affected by exogenous sCD14.

Protein measurements with ELISA showed that in the absence of sCD14, IL-6, CXCL8, and CCL2 protein levels were significantly increased after stimulation with Pam3CSK4 starting from $10 \mathrm{ng} / \mathrm{ml}$ in a concentrationdependent manner. The presence of sCD14 during stimulation resulted in significantly enhanced levels of all proteins in response to all tested Pam3CSK 4 concentrations excepting the highest one $(1000 \mathrm{ng} / \mathrm{ml})$.

3.2. Effect of sCD14 on the hPDLSC Response to TLR-2 Agonist LTA. Gene and protein expression levels of IL-6, CXCL8, and CCL2 in primary hPDLSCs, stimulated with different LTA concentrations in the presence/absence of sCD14 $(250 \mathrm{ng} / \mathrm{ml})$, are shown in Figure 2. In the absence of sCD14, LTA induced a concentration-dependent increase in IL-6, CXCL8, and CCL2 gene expression levels. The highest response was observed at $1000 \mathrm{ng} / \mathrm{ml}$ LTA. A significant increase in the expression of all three target genes was observed after stimulation from 10 to $1000 \mathrm{ng} / \mathrm{ml}$ LTA. Adding the exogenous sCD14 during stimulation significantly enhanced the expression levels of all three target genes in response to all tested LTA concentrations.

As measured by ELISA, in the absence of sCD14, IL-6, CXCL8, and CCL2 protein levels were significantly increased after stimulation with LTA in a dose-dependent manner. A significant increase started at $100 \mathrm{ng} / \mathrm{ml}$ for IL-6 and CXCL8 and at $1 \mathrm{ng} / \mathrm{ml}$ for CCL2. The presence of exogenous sCD14 during stimulation resulted in significantly enhanced levels of IL-6 and CCL2 in response to all tested LTA concentrations excepting the highest one. Additionally, sCD14 significantly increased CXCL8 protein production induced by all tested LTA concentrations.

\subsection{Effect of Different sCD14 Concentrations on the hPDLSC} Response to Submaximal Concentration of Pam3CSK4. The dependency of the hPDLSC response to submaximal Pam3CSK4 concentration $(10 \mathrm{ng} / \mathrm{ml})$ on different sCD14 levels is shown in Figure 3. Stimulation of hPDLSCs with Pam3CSK 4 in the absence of sCD14 resulted in increased IL-6, CXCL8, and CCL2 gene expression levels. This response to Pam3CSK4 was increased by $\mathrm{sCD} 14$ in a concentration-dependent manner. A significant increase was observed starting from $10 \mathrm{ng} / \mathrm{ml}$ sCD14 for IL-6 and from $2.5 \mathrm{ng} / \mathrm{ml}$ for CXCL8 and CCL2.

In the absence of sCD $14,10 \mathrm{ng} / \mathrm{ml}$ Pam3CSK 4 already induced protein expression of IL-6, CXCL8, and CCL2 in a concentration-dependent manner. A significant increase of all three investigated proteins was observed starting from sCD14 concentration as low as $25 \mathrm{ng} / \mathrm{ml}$.

\subsection{Effect of Different sCD14 Concentrations on the hPDLSC} Response to Submaximal Concentration of LTA. The dependency of hPDLSC response to submaximal LTA concentration $(10 \mathrm{ng} / \mathrm{ml})$ on different sCD14 levels is shown in Figure 4. LTA treatment of hPDLSCs in the absence of sCD14 caused an increase in gene expressions of IL-6, CXCL8, and CCL2. This response to LTA was increased by sCD14 in a concentration-dependent manner, showing significances at higher sCD14 levels for all three genes. Gene expression of CCL2 was already significantly increased at the lowest tested sCD14 level $(2.5 \mathrm{ng} / \mathrm{ml})$.

Protein expressions of all three targets were increased upon LTA stimulation and were further enhanced by exogenous sCD14 in a concentration-dependent manner. Statistically significant differences were observed starting 

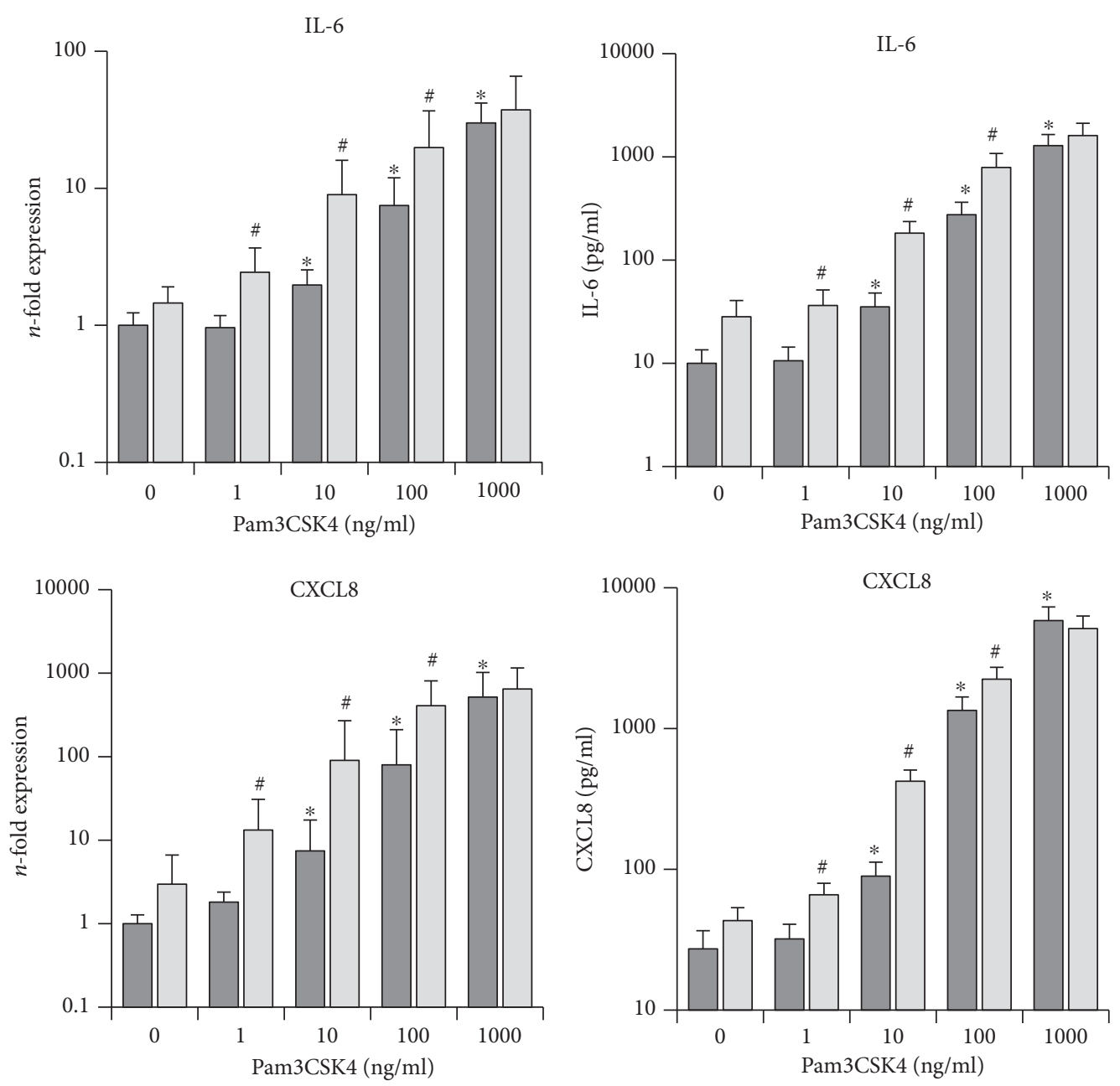



(a)

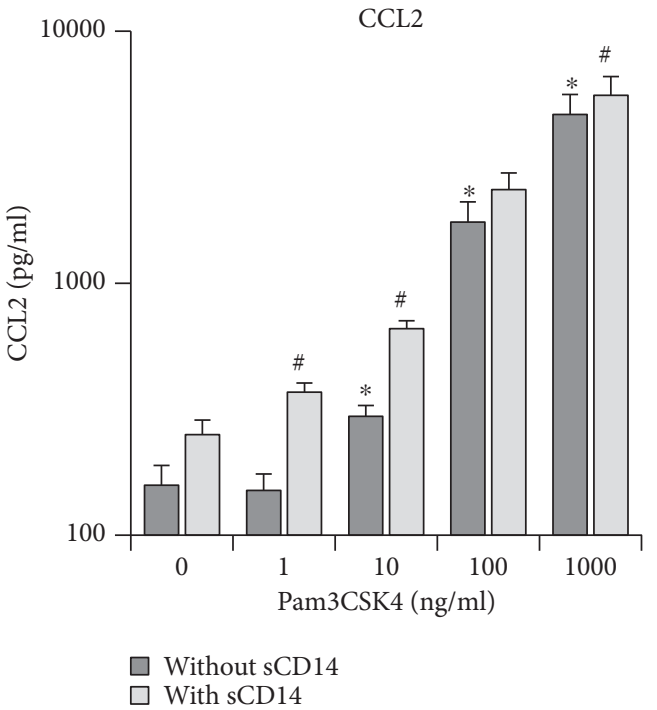

(b)

FIgURE 1: Effect of sCD14 on the hPDLSC response to TLR-2 agonist Pam3CSK4. Primary hPDLSCs were stimulated with different Pam3CSK4 concentrations (1-1000 ng/ml), in the presence/absence of sCD14 (250 ng/ml). Untreated cells served as the control. After 24 hours of incubation, IL-6, CXCL8, and CCL2 gene expression levels (a) were measured using qPCR. The $y$-axis shows the $n$-fold expression of the target genes compared to the unstimulated control. The corresponding protein levels in conditioned media (b) were determined by ELISA. All data are presented as mean \pm s.e.m. from five independent experiments using cells from five different donors. ${ }^{*} p$ value $<0.05$ compared to control. \# $p$ value $<0.05$ compared to the appropriate group stimulated in the absence of sCD14. 

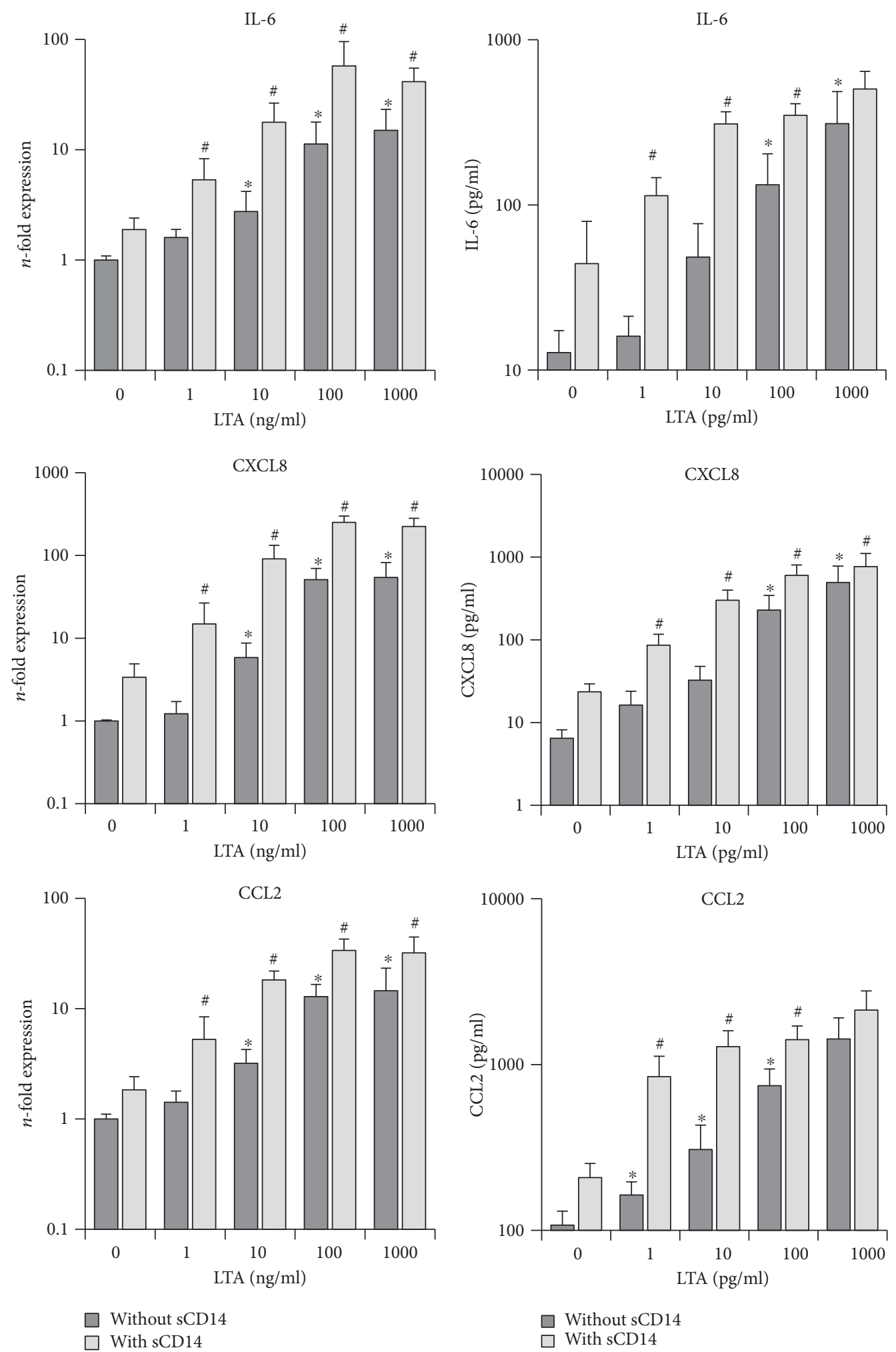

(a)

(b)

Figure 2: Effect of sCD14 on the hPDLSC response to TLR-2 agonist LTA. Primary hPDLSCs were stimulated with different LTA concentrations $(1-1000 \mathrm{ng} / \mathrm{ml})$, in the presence/absence of sCD14 $(250 \mathrm{ng} / \mathrm{ml})$. Untreated cells served as the control. After 24 hours of incubation, IL-6, CXCL8, and CCL2 gene expression levels (a) were measured using qPCR. The $y$-axis shows the $n$-fold expression of the target genes compared to the unstimulated control. The corresponding protein levels in conditioned media (b) were determined by ELISA. All data are presented as mean \pm s.e.m. from five independent experiments using cells from five different donors. ${ }^{*} p$ value $<0.05$ compared to the control. \# $p$ value $<0.05$ compared to the appropriate group stimulated in the absence of sCD14. 

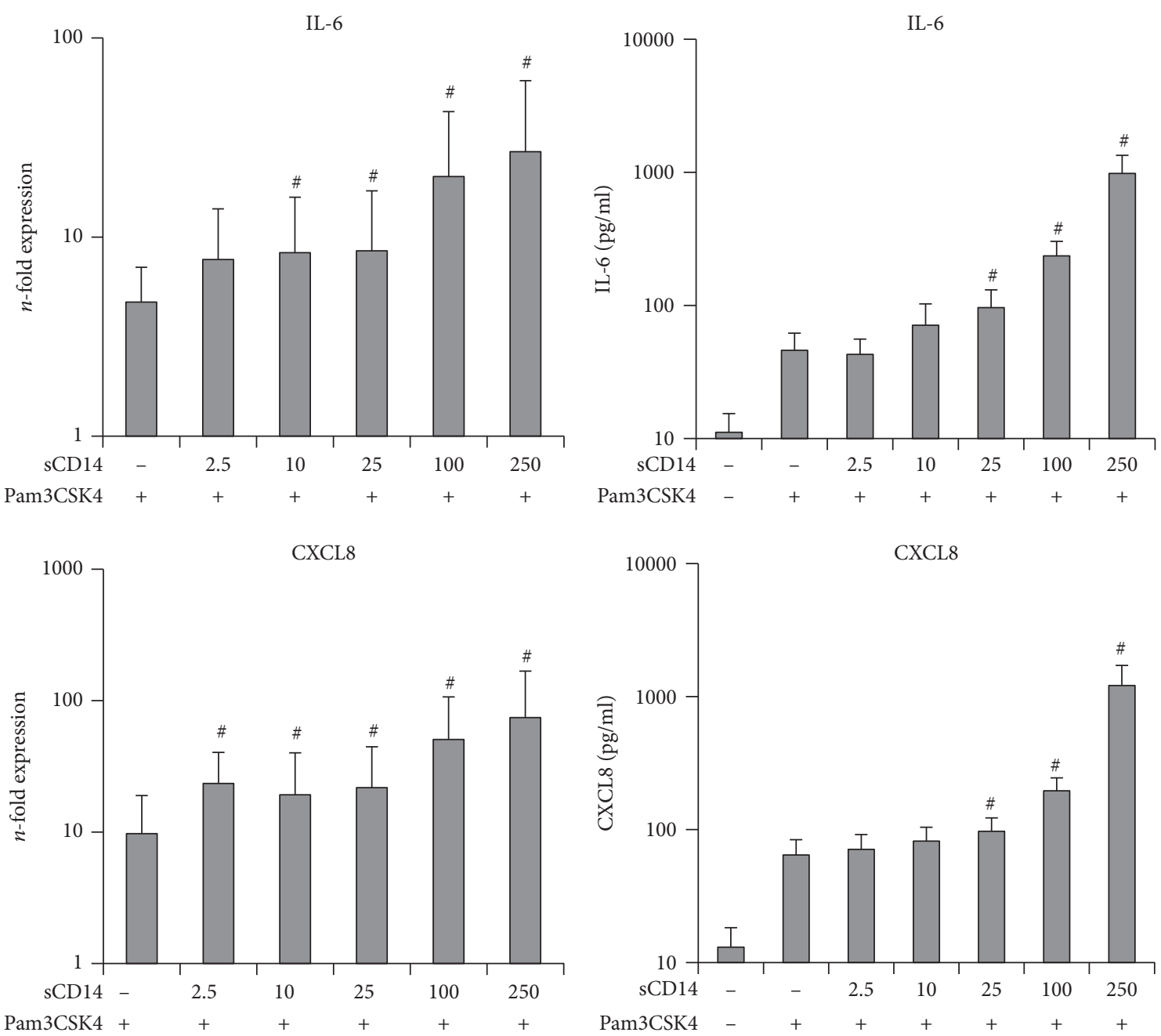

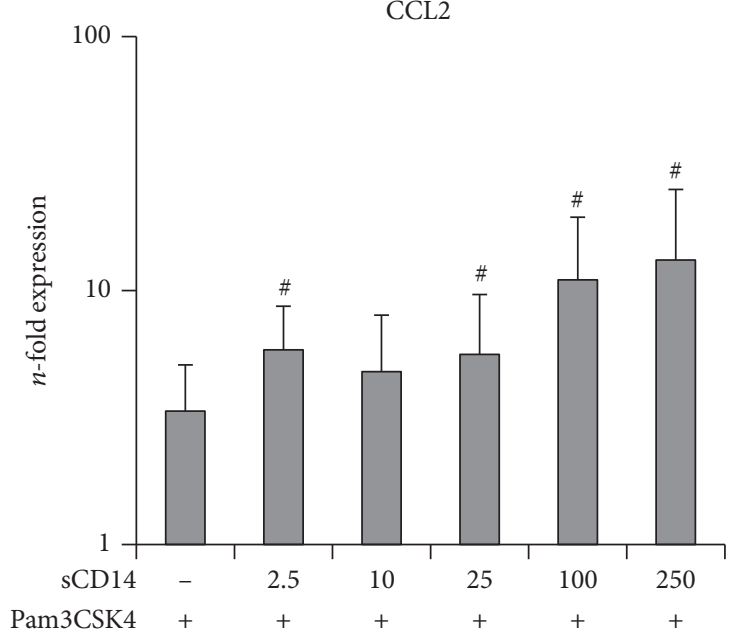

(a)

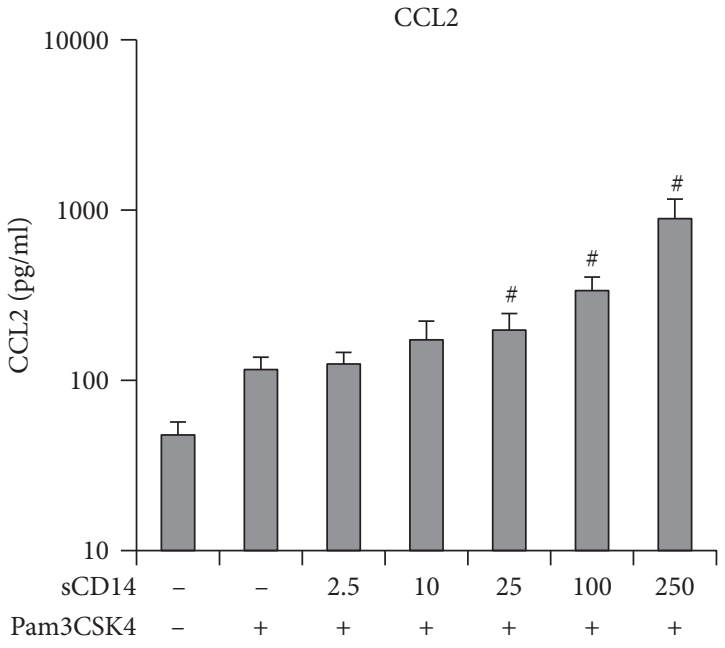

(b)

FIGURE 3: Effect of different sCD14 concentrations on the hPDLSC response to submaximal Pam3CSK4 concentration. Primary hPDLSCs were stimulated with Pam3CSK4 at submaximal concentration $(10 \mathrm{ng} / \mathrm{ml})$ and different concentrations of sCD14 (2.5-250 ng/ml). Untreated cells served as the control. After 24 hours of incubation, IL-6, CXCL8, and CCL2 gene expression levels (a) were determined using qPCR. The $y$-axis shows the $n$-fold expression of the target genes compared to the unstimulated control. The corresponding protein levels in conditioned media (b) were determined by ELISA. All data are presented as mean \pm s.e.m. from five independent experiments using cells from five different donors. \# $p$ value $<0.05$ compared to cells stimulated with Pam3CSK4 in the absence of sCD14. 

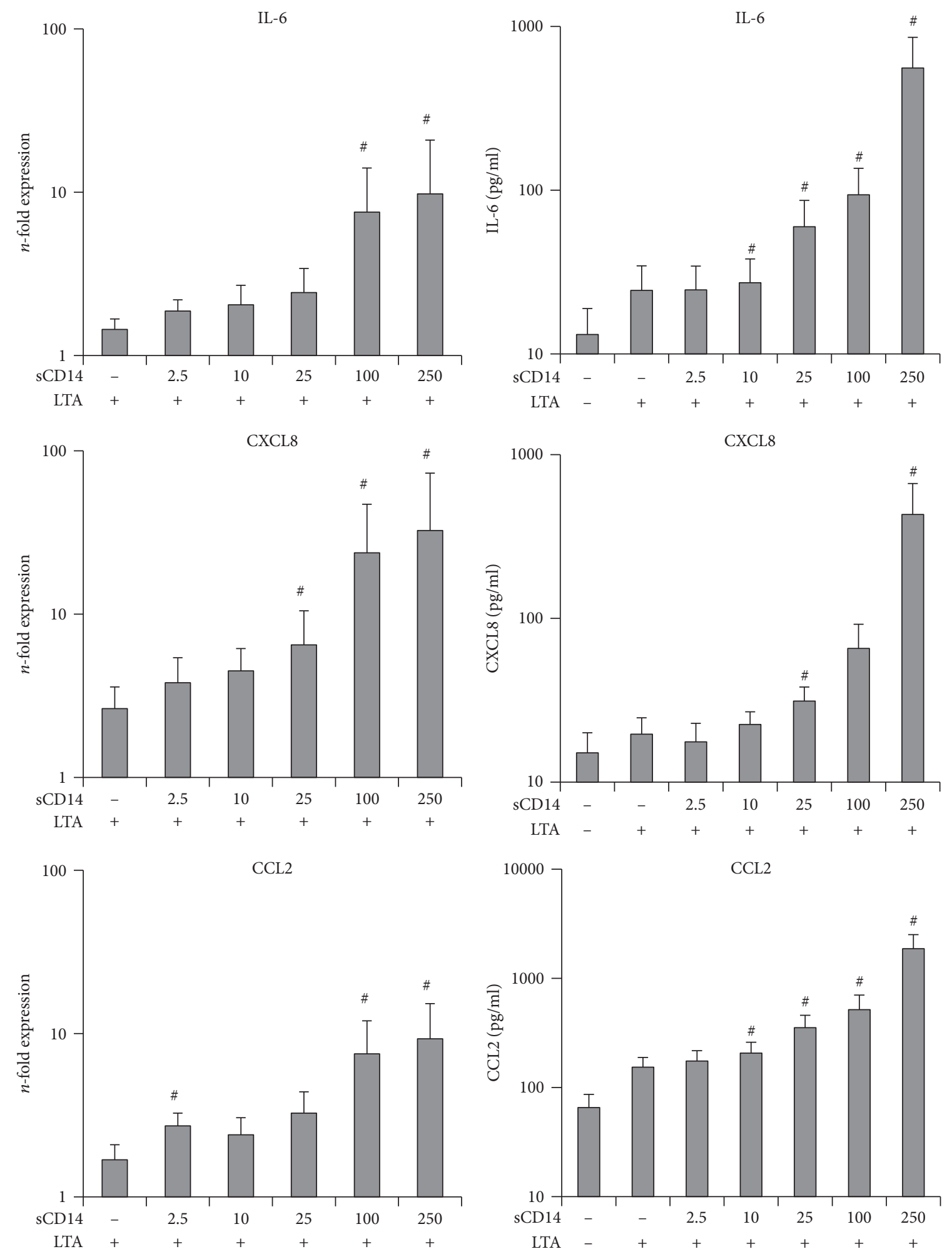

(a)

(b)

FIGURE 4: Effect of different sCD14 levels on the hPDLSC response to submaximal LTA concentration. Primary hPDLSCs were stimulated with LTA at submaximal concentration $(10 \mathrm{ng} / \mathrm{ml})$ and different concentrations of sCD14 $(2.5-250 \mathrm{ng} / \mathrm{ml})$. Untreated cells served as the control. After 24 hours of incubation, IL-6, CXCL8, and CCL2 gene expression levels (a) were measured using qPCR. The $y$-axis shows the $n$-fold expression of the target genes compared to the unstimulated control. The corresponding protein levels in conditioned media (b) were determined by ELISA. All data are presented as mean \pm s.e.m. from five independent experiments using cells from five different donors. \#p value $<0.05$ compared to cells stimulated with LTA in the absence of sCD14. 

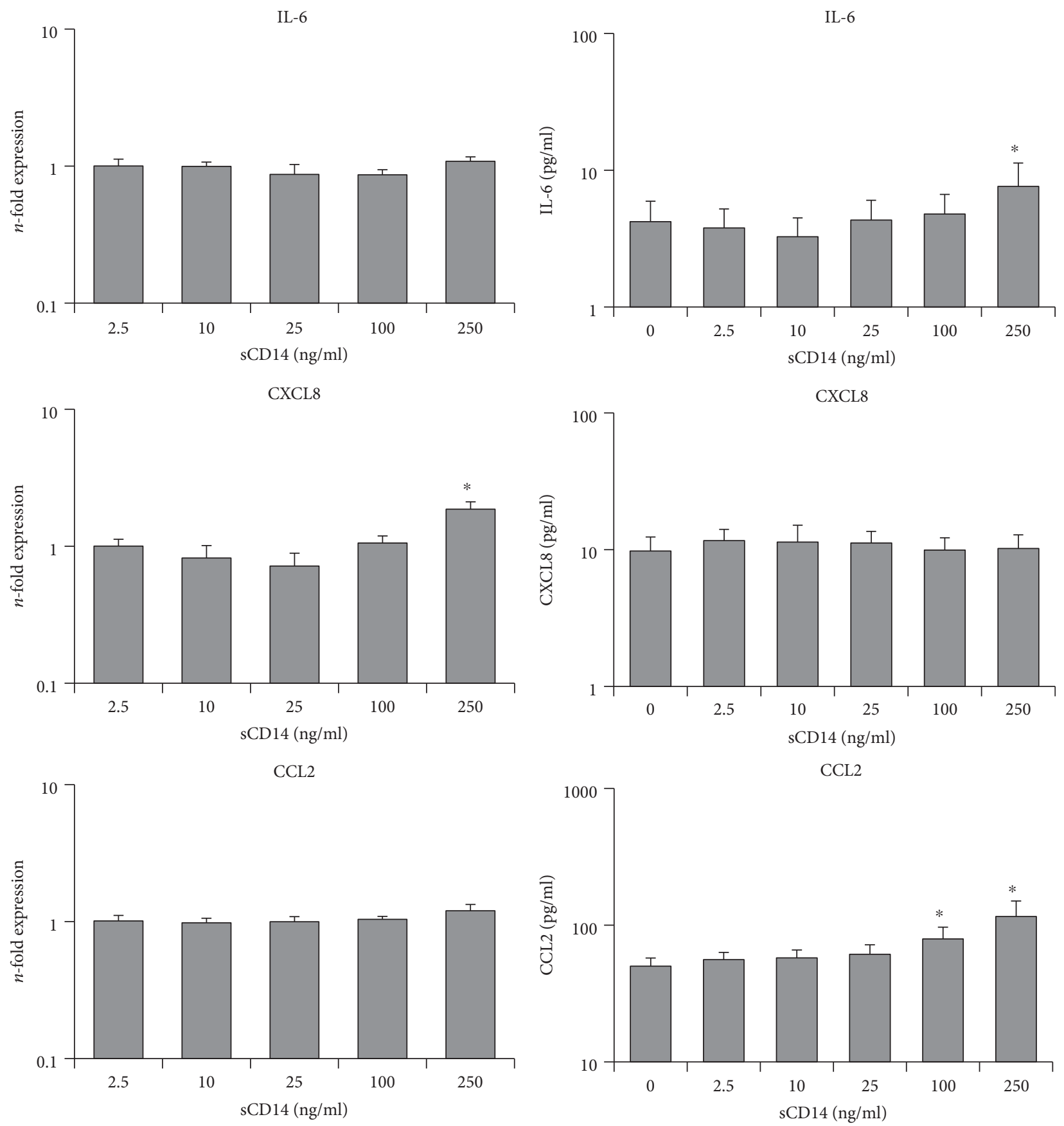

(a)

(b)

FIGURE 5: Response of hPDLSCs to different sCD14 concentrations. Primary hPDLSCs were stimulated for 24 hours with different sCD14 concentrations $(2.5 \mathrm{ng} / \mathrm{ml}-250 \mathrm{ng} / \mathrm{ml})$ in the absence of TLR-2 agonists. Untreated cells served as the control. After 24 hours of incubation, IL-6, CXCL8, and CCL2 gene expression levels (a) were measured using qPCR. The $y$-axis shows the $n$-fold expression of the target genes compared to the unstimulated control. The corresponding protein levels in conditioned media (b) were determined by ELISA. All data are presented as mean \pm s.e.m. from five independent experiments using cells from five different donors. ${ }^{*} p$ value $<0.05$ compared to the control.

from $10 \mathrm{ng} / \mathrm{ml} \mathrm{sCD} 14$ for IL-6 and CCL2 and from $25 \mathrm{ng} / \mathrm{ml}$ sCD14 for CXCL8.

3.5. Response of hPDLSCs to Exogenous sCD14. Figure 5 shows the response of hPDLSCs to exogenous sCD14 without any TLR-2 agonist. Under these conditions, low concentrations of exogenous sCD14 have no significant effect on IL-6, CXCL8, and CCL2 expressions, on gene and protein levels. However, significances were observed only for the highest tested sCD14 levels $(250 \mathrm{ng} / \mathrm{ml})$ for IL-6 protein and CXCL8 gene expressions as wells as starting at $100-250 \mathrm{ng} / \mathrm{ml}$ for CCL2 protein expression. 


\section{Discussion}

In our previous study, we showed a significant sCD14mediated increase in the bacterial LPS- induced TLR-4 response in hPDLSCs [19]. Although several studies on different immune cells showed an impact of sCD14 on TLR-2 [36-39], the contribution of sCD14 on the TLR-2 response in hPDLSCs has not been investigated so far. Hence, we investigated for the first time in vitro the potential impact of sCD14 on Pam3CSK4- or LTA-induced TLR-2 response in hPDLSCs. Our data demonstrated that exogenous sCD14 substantially enhances the production of inflammatory mediators by hPDLSCs in response to stimulation even with small amounts of TLR-2 agonists. This finding further indicates an important role of sCD14 in the host inflammatory response to different bacterial components.

The production of the inflammatory mediators IL-6, CXCL8, and CCL2 was substantially increased by exogenous sCD14 in response to both tested TLR-2 agonists. The enhancement of the response was observed for all tested Pam3CSK4 and LTA concentrations excepting the highest tested Pam3CSK 4 concentration of $1000 \mathrm{ng} / \mathrm{ml}$. The presence of exogenous sCD14 allowed hPDLSCs to sense different TLR-2 agonists at very low concentrations, starting from $1 \mathrm{ng} / \mathrm{ml}$, and thus, might sense very low amounts of bacterial pathogens. Such situation is imaginable immediately after epithelial barrier destruction and bacterial invasion into periodontal tissue. Production of different inflammatory mediators by hPDLSCs under these conditions will substantially contribute to the further host inflammatory response and disease progression.

In our study, we focused on the expression of three proteins, IL-6, CXCL8, and CCL2, which are thought to play an essential role in periodontal tissue inflammation and are usually regarded as the factors which enhance the inflammatory response in periodontitis $[41,42]$. IL-6 is an important proinflammatory cytokine, involved in the acute inflammation phase and bone resorption [41]. CXCL8 and CCL2 are both chemokines, attracting neutrophils and macrophages, respectively, to the site of inflammation, promoting acute inflammation [42, 43]. However, studies of the last years suggest that besides classical proinflammatory effects, these proteins play some anti-inflammatory roles and/or contribute to periodontal tissue homeostasis. Particularly, there are increasing evidences that IL-6 is involved in MSCdependent suppression of $\mathrm{T}$ cell proliferation. There are also evidences that IL-6 suppresses neutrophil apoptosis and respiratory burst and facilitates regulatory dendritic cell and anti-inflammatory macrophage formation [44-47]. Lower CXCL8 levels are thought to diminish neutrophil recruitment to the periodontal pocket, which may lead to overgrowth of some pathogenic microorganisms.

Based on this dual role of all investigated mediators, it is difficult to assess the exact role of local sCD14 levels and the enhancement of TLR-2-induced response by sCD14. It might on the one hand promote the inflammation response and on the other hand contribute to the maintenance of periodontal tissue homeostasis. The dual role of the immune response should be also noted, which on the one hand is aimed at eliminating pathogens and on the other hand leads to collateral tissue damages [48]. Hence, the physiological functions and the exact role in periodontal tissue inflammation of IL-6, CXCL8, and CCL2, produced by hPDLSCs in response to different virulence factors, need to be further investigated.

Our data showed a significant effect of sCD14 on the TLR-2 response in hPDLSCs regardless of the TLR- 2 agonist. This may occur obviously by facilitating the interaction between lipoproteins and TLR-2 on the hPDLSC surface by sCD14 [36-38, 40]. However, the hPDLSC response to $1000 \mathrm{ng} / \mathrm{ml}$ Pam3CSK4 was not further enhanced by sCD14, which was also observed in our previous study [19]. This finding can be explained by the fact that Pam3CSK 4 at this concentration induces a maximal TLR-2 response and that TLR-2 signalling seems to be fully activated even in the absence of sCD14. This observation is in line with other studies, exhibiting CD14 as critical for the response to low LPS doses and less important for high LPS doses [49] and that sCD14 makes immune cells more susceptible to triacetylated lipopeptides on the nanogram level [38].

In contrast to Pam3CSK4, sCD14 significantly enhanced the hPDLSC response to LTA at $1000 \mathrm{ng} / \mathrm{ml}$. However, it should be noted that in the absence of sCD14, the production of different proinflammatory mediators by hPDLSCs in response to $1000 \mathrm{ng} / \mathrm{ml}$ LTA was up to $90 \%$ lower than that induced by similar concentration of Pam3CSK4. Therefore, it can be assumed that LTA at $1000 \mathrm{ng} / \mathrm{ml}$ did not induce a maximal activation of TLR-2-dependent response, which can be further increased by adding exogenous sCD14. The differences in the hPDLSC response might be explained by the distinct chemical nature of the two used TLR-2 agonists and the resulting different activation mechanisms [36-38, 40, 50].

The molecular mechanisms of the cell response activation by TLR- 2 agonists are differently discussed in the literature. Triacylated lipoprotein Pam3CSK4 coordinately binds to TLR-2 as well as to TLR-1, leading to a heterodimerization of these two receptors and resulting in the formation of a stable ternary signalling complex, consisting of TLR-2, TLR-1, and triacetylated lipoprotein $[36,38,50]$. sCD14 as well as lipopolysaccharide-binding protein (LBP) sensitize cells to lipoproteins $[51,52]$ by disaggregating lipoproteins and delivering monomeric lipoproteins to the receptors $[36,38]$. In contrast to the membrane-bound CD14, which is physically associated with the TLR heterodimer [53], sCD14 facilitates the formation of the ternary signalling complex without being a part of the complex itself. A study of Ranoa et al. suggests that during agonist delivery to the receptors, sCD14 stably interacts with TLR-1 but is replaced by TLR-2 during ternary complex formation [38]. Concerning LTA, several functional studies show an LTA-activated cellular response through TLR-2 recognition without the involvement of other TLRs but in the presence of sCD14 [37, 40, 54]. However, the knowledge about the precise interactions of involved proteins is limited. One study demonstrates the complex formation of LTA with LBP and catalytic transfer of LTA to sCD14 through LBP, resulting in the formation of a LTA-sCD14 complex [37]. Although both TLR-2 agonists seem to differ in the TLR activation mechanism, 
they cause NF- $\kappa$ B translocation into the nucleus and further the expression of proinflammatory cytokines $[37,55]$.

We further investigated the dependency of the hPDLSC response to submaximal concentrations of TLR-2 agonists on different local sCD14 levels. We found a clear dosedependent increase of the TLR-2 response from the lowest to the highest sCD14 concentrations. On the protein level, a significant increase in hPDLSC response to submaximal concentrations of TLR-2 agonists was induced by $25 \mathrm{ng} / \mathrm{ml}$ of sCD14, which is a rather low level compared to those detected in physiological fluids. Particularly, the local sCD14 concentration in gingival crevicular fluid and blood serum is in $\mu \mathrm{g} / \mathrm{ml}[56,57]$. Since the effect of sCD14 levels on the hPDLSC response to both TLR-2 agonists and bacterial LPS [19] is concentration-dependent, we suggest that alterations of local sCD14 levels might play an important role in periodontitis through sensitizing hPDLSCs to periodontal pathogens. For example, an increase in sCD14 will facilitate the recognition of periodontal bacteria-associated lipoproteins of LPS by hPDLSCs. This enhances the production of diverse inflammatory mediators, including IL-6, CXCL8, and CCL2, which may contribute to the overwhelming immune response and consequently to progression of periodontitis. This assumption is supported by different clinical studies, which mostly show a positive association between sCD14 levels and periodontal disease [57-59]. Particularly, Isaza-Guzmán et al. detected significant higher sCD14 levels in the saliva of periodontitis patients compared to healthy controls [58], whereas other studies also showed a significantly higher sCD14 concentrations in the serum of subjects with chronic periodontitis [57, 59]. Additionally, a positive correlation between $\mathrm{sCD} 14$ saliva levels and different clinical parameters of periodontitis severity was demonstrated [58]. Interestingly, Jin and Darveau exhibited a negative correlation between sCD14 levels in gingival crevicular fluids and the number and depth of periodontal pockets in patients suffering from periodontitis [56]. These inconsistencies, concerning the relationship between local SCD14 levels and periodontitis severity, may be explained by the dual nature of the immunomodulatory properties of hPDLSCs. On the one hand, hPDLSCs produce proinflammatory mediators under certain conditions, promoting the inflammatory response. On the other hand, hPDLSCs are known to produce immunosuppressive proteins, which diminish the local inflammatory response [60]. Regulation of the immunomodulatory activity of hPDLSCs by TLR activation may effect periodontal disease progression $[19,27]$. This assumption is supported by studies, showing an impaired immunomodulation of hPDLSCs in periodontitis patients $[61,62]$.

It seems that there are some differences in the affinity of sCD14 to different TLRs in hPDLSCs. In our previous study, we show that the maximal effect of sCD14 on the TLR-4 response to bacterial LPS is already achieved at concentrations of $25 \mathrm{ng} / \mathrm{ml}$ [19]. In contrast, in the present study, a gradual increase in hPDLSC response to both TLR-2 agonists was observed with a gradual increase of the sCD14 concentration from 2.5 to $250 \mathrm{ng} / \mathrm{ml}$. Although sCD14 facilitates the formation of a stable ternary signalling complex for both TLRs, without being a part of the complex itself $[36,38,63]$, the activation mechanisms of both TLRs differ from each other, due to the different natures of their agonists or the involvement of the MD-2 protein in the TLR-4 signalling complex [64]. These differences may possibly explain the higher sensitivity of the TLR-4 response to sCD14 than TLR-2.

We further investigated a potential influence of sCD14 on the expression of inflammatory markers in hPDLSCs in the absence of TLR-2 agonists. Surprisingly, we found a significant increase in the secretion of IL- 6 and CCL2 and a significant increase in the expression of CXCL8 at the highest used sCD14 concentrations. However, the expression levels, triggered solely by $\mathrm{sCD} 14$, were rather negligible compared with its effect on Pam3CSK4- or LTA-induced responses. Therefore, we conclude that the enhancement of the TLR-2 responses by $\mathrm{sCD} 14$ is due to its interaction with the TLR-2 receptor. Additionally, the stable interaction of sCD14 with TLR-1 until the heterodimerization with TLR-2 [38] may influence the expression of inflammatory markers, at least at high $\mathrm{SCD} 14$ concentrations.

\section{Conclusion}

In conclusion, our study shows that sCD14 enhances the response of hPDLSCs to submaximal concentrations of TLR-2 agonists in a concentration-dependent manner. The stimulating effect was detectable at sCD14 levels, which are comparable to those in saliva and gingival crevicular fluid. The presence of sCD14 sensitizes hPDLSCs to bacterial pathogens and enables their response even to low amounts of TLR-2 agonists in the range of few nanograms per millilitres. We suggest that different local sCD14 levels may affect the strength of TLR-2-mediated immune response in hPDLSCs, leading to a stronger IL-6, CXCL8, and CCL2 production at higher sCD14 levels. These higher proinflammatory cytokine levels may contribute to the overwhelming immune response and consequently affect the development of periodontitis.

\section{Data Availability}

The data used to support the findings of this study are available from the corresponding author upon request.

\section{Conflicts of Interest}

The authors declare that there is no conflict of interest regarding the publication of this paper.

\section{Acknowledgments}

The authors thank Mrs. Phuong Quynh Nguyen for excellent technical assistance. This study was funded by the Austrian Science Fund (FWF) (P 29440 to Oleh Andrukhov).

\section{References}

[1] D. J. Prockop, "Marrow stromal cells as stem cells for nonhematopoietic tissues," Science, vol. 276, no. 5309, pp. 7174, 1997. 
[2] S. Gronthos, M. Mankani, J. Brahim, P. G. Robey, and S. Shi, "Postnatal human dental pulp stem cells (DPSCs) in vitro and in vivo," Proceedings of the National Academy of Sciences of the United States of America, vol. 97, no. 25, pp. 1362513630, 2000.

[3] L. Tang, N. Li, H. Xie, and Y. Jin, "Characterization of mesenchymal stem cells from human normal and hyperplastic gingiva," Journal of Cellular Physiology, vol. 226, no. 3, pp. 832-842, 2011.

[4] C. Morsczeck, W. Götz, J. Schierholz et al., "Isolation of precursor cells (PCs) from human dental follicle of wisdom teeth," Matrix Biology, vol. 24, no. 2, pp. 155-165, 2005.

[5] B.-M. Seo, M. Miura, S. Gronthos et al., "Investigation of multipotent postnatal stem cells from human periodontal ligament," The Lancet, vol. 364, no. 9429, pp. 149-155, 2004.

[6] N. Wada, S. Gronthos, and P. M. Bartold, "Immunomodulatory effects of stem cells," Periodontology 2000, vol. 63, no. 1, pp. 198-216, 2013.

[7] M. Dominici, K. Le Blanc, I. Mueller et al., "Minimal criteria for defining multipotent mesenchymal stromal cells. The International Society for Cellular Therapy position statement," Cytotherapy, vol. 8, no. 4, pp. 315-317, 2006.

[8] G. Z. Racz, K. Kadar, A. Foldes et al., "Immunomodulatory and potential therapeutic role of mesenchymal stem cells in periodontitis," Journal of Physiology and Pharmacology, vol. 65, no. 3, pp. 327-339, 2014.

[9] W. Zhu and M. Liang, "Periodontal ligament stem cells: current status, concerns, and future prospects," Stem Cells International, vol. 2015, Article ID 972313, 11 pages, 2015.

[10] S. C. Holt and J. L. Ebersole, "Porphyromonas gingivalis, Treponema denticola, and Tannerella forsythia: the 'red complex', a prototype polybacterial pathogenic consortium in periodontitis," Periodontology 2000, vol. 38, no. 1, pp. 72-122, 2005.

[11] D. F. Kinane, "Causation and pathogenesis of periodontal disease," Periodontology 2000, vol. 25, no. 1, pp. 8-20, 2001.

[12] H. Hasturk and A. Kantarci, "Activation and resolution of periodontal inflammation and its systemic impact," Periodontology 2000, vol. 69, no. 1, pp. 255-273, 2015.

[13] D. F. Kinane, H. Shiba, and T. C. Hart, "The genetic basis of periodontitis," Periodontology 2000, vol. 39, no. 1, pp. 91117, 2005.

[14] F. H. Nociti Jr., M. Z. Casati, and P. M. Duarte, "Current perspective of the impact of smoking on the progression and treatment of periodontitis," Periodontology 2000, vol. 67, no. 1, pp. 187-210, 2015.

[15] S. S. Socransky, A. D. Haffajee, M. A. Cugini, C. Smith, and R. L. Kent, "Microbial complexes in subgingival plaque," Journal of Clinical Periodontology, vol. 25, no. 2, pp. 134144, 1998.

[16] S. J. Byrne, S. G. Dashper, I. B. Darby, G. G. Adams, B. Hoffmann, and E. C. Reynolds, "Progression of chronic periodontitis can be predicted by the levels of Porphyromonas gingivalis and Treponema denticola in subgingival plaque," Oral Microbiology and Immunology, vol. 24, no. 6, pp. 469477, 2009.

[17] G. Hajishengallis and R. J. Lamont, "Breaking bad: manipulation of the host response by Porphyromonas gingivalis," European Journal of Immunology, vol. 44, no. 2, pp. 328338, 2014.

[18] H. Kato, Y. Taguchi, K. Tominaga, M. Umeda, and A. Tanaka, "Porphyromonas gingivalis LPS inhibits osteoblastic differentiation and promotes pro-inflammatory cytokine production in human periodontal ligament stem cells," Archives of Oral Biology, vol. 59, no. 2, pp. 167-175, 2014.

[19] O. Andrukhov, O. Andrukhova, B. Özdemir et al., "Soluble CD14 enhances the response of periodontal ligament stem cells to P. gingivalis lipopolysaccharide," PLoS One, vol. 11, no. 8, article e0160848, 2016.

[20] S. Jain, S. R. Coats, A. M. Chang, and R. P. Darveau, "A novel class of lipoprotein lipase-sensitive molecules mediates toll-like receptor 2 activation by Porphyromonas gingivalis," Infection and Immunity, vol. 81, no. 4, pp. 12771286, 2013.

[21] A. C. F. Morandini, P. P. Chaves Souza, E. S. Ramos-Junior et al., "Toll-like receptor 2 knockdown modulates interleukin (IL)-6 and IL-8 but not stromal derived factor-1 (SDF1/CXCL12) in human periodontal ligament and gingival fibroblasts," Journal of Periodontology, vol. 84, no. 4, pp. 535-544, 2013.

[22] T. D. K. Herath, R. P. Darveau, C. J. Seneviratne, C. Y. Wang, Y. Wang, and L. Jin, "Tetra- and penta-acylated lipid A structures of Porphyromonas gingivalis LPS differentially activate TLR4-mediated NF- $\kappa \mathrm{B}$ signal transduction cascade and immuno-inflammatory response in human gingival fibroblasts," PLoS One, vol. 8, no. 3, article e58496, 2013.

[23] A. Poltorak, X. He, I. Smirnova et al., "Defective LPS signaling in C3H/HeJ and C57BL/10ScCr mice: mutations in Tlr4 gene," Science, vol. 282, no. 5396, pp. 2085-2088, 1998.

[24] B. S. Park and J. O. Lee, "Recognition of lipopolysaccharide pattern by TLR4 complexes," Experimental \& Molecular Medicine, vol. 45, no. 12, article e66, 2013.

[25] S. Akira and K. Takeda, “Toll-like receptor signalling," Nature Reviews Immunology, vol. 4, no. 7, pp. 499-511, 2004.

[26] A. P. West, A. A. Koblansky, and S. Ghosh, "Recognition and signaling by Toll-like receptors," Annual Review of Cell and Developmental Biology, vol. 22, no. 1, pp. 409-437, 2006.

[27] O. DelaRosa, W. Dalemans, and E. Lombardo, "Toll-like receptors as modulators of mesenchymal stem cells," Frontiers in Immunology, vol. 3, 2012.

[28] L. Tang, X. D. Zhou, Q. Wang et al., "Expression of TRAF6 and pro-inflammatory cytokines through activation of TLR2, TLR4, NOD1, and NOD2 in human periodontal ligament fibroblasts," Archives of Oral Biology, vol. 56, no. 10, pp. 1064-1072, 2011.

[29] K. M. Fawzy El-Sayed, M. Elahmady, Z. Adawi et al., "The periodontal stem/progenitor cell inflammatory-regenerative cross talk: a new perspective," Journal of Periodontal Research, vol. 54, no. 10, pp. 81-94, 2019.

[30] K. Fawzy-El-Sayed, M. Mekhemar, S. Adam-Klages, D. Kabelitz, and C. Dorfer, "TLR expression profile of human gingival margin-derived stem progenitor cells," Medicina Oral Patología Oral y Cirugia Bucal, vol. 21, pp. e30-e38, 2016.

[31] S. Wright, R. Ramos, P. Tobias, R. Ulevitch, and J. Mathison, "CD14, a receptor for complexes of lipopolysaccharide (LPS) and LPS binding protein," Science, vol. 249, no. 4975, pp. 1431-1433, 1990.

[32] B. Beutler and E. T. Rietschel, "Innate immune sensing and its roots: the story of endotoxin," Nature Reviews Immunology, vol. 3, no. 2, pp. 169-176, 2003.

[33] R. I. Tapping and P. S. Tobias, "Soluble CD14-mediated cellular responses to lipopolysaccharide," Chemical Immunology, vol. 74, pp. 108-121, 2000. 
[34] B. Song, Y. L. Zhang, L. J. Chen et al., "The role of Toll-like receptors in periodontitis," Oral Diseases, vol. 23, no. 2, pp. 168-180, 2017.

[35] E. Shimada, H. Kataoka, Y. Miyazawa, M. Yamamoto, and T. Igarashi, "Lipoproteins of Actinomyces viscosus induce inflammatory responses through TLR2 in human gingival epithelial cells and macrophages," Microbes and Infection, vol. 14, no. 11, pp. 916-921, 2012.

[36] T. Nakata, M. Yasuda, M. Fujita et al., "CD14 directly binds to triacylated lipopeptides and facilitates recognition of the lipopeptides by the receptor complex of Toll-like receptors 2 and 1 without binding to the complex," Cellular Microbiology, vol. 8, no. 12, pp. 1899-1909, 2006.

[37] N. W. J. Schröder, S. Morath, C. Alexander et al., "Lipoteichoic acid (LTA) of Streptococcus pneumoniae and Staphylococcus aureus activates immune cells via Toll-like receptor (TLR)-2, lipopolysaccharide-binding protein (LBP), and CD14, whereas TLR-4 and MD-2 are not involved," The Journal of Biological Chemistry, vol. 278, no. 18, pp. 1558715594, 2003.

[38] D. R. E. Ranoa, S. L. Kelley, and R. I. Tapping, "Human lipopolysaccharide-binding protein (LBP) and CD14 independently deliver triacylated lipoproteins to toll-like receptor 1 (TLR1) and TLR2 and enhance formation of the ternary signaling complex," The Journal of Biological Chemistry, vol. 288, no. 14, pp. 9729-9741, 2013.

[39] L. Janot, T. Secher, D. Torres et al., "CD14 works with Toll-like receptor 2 to contribute to recognition and control of Listeria monocytogenes infection," The Journal of Infectious Diseases, vol. 198, no. 1, pp. 115-124, 2008.

[40] E. Ellingsen, S. Morath, T. Flo et al., "Induction of cytokine production in human $\mathrm{T}$ cells and monocytes by highly purified lipoteichoic acid: involvement of Toll-like receptors and CD14," Medical Science Monitor, vol. 8, no. 5, pp. BR149BR156, 2002.

[41] J. E. Fonseca, M. J. Santos, H. Canhão, and E. Choy, "Interleukin-6 as a key player in systemic inflammation and joint destruction," Autoimmunity Reviews, vol. 8, no. 7, pp. 538$542,2009$.

[42] T. A. Silva, G. P. Garlet, S. Y. Fukada, J. S. Silva, and F. Q. Cunha, "Chemokines in oral inflammatory diseases: apical periodontitis and periodontal disease," Journal of Dental Research, vol. 86, no. 4, pp. 306-319, 2007.

[43] M. Baggiolini, B. Dewald, and B. Moser, "Interleukin-8 and related chemotactic cytokines-CXC and CC chemokines," Advances in Immunology, vol. 55, pp. 97-179, 1993.

[44] P. Muñoz-Cánoves, C. Scheele, B. K. Pedersen, and A. L. Serrano, "Interleukin-6 myokine signaling in skeletal muscle: a double-edged sword?", The FEBS Journal, vol. 280, no. 17, pp. 4131-4148, 2013.

[45] M. Najar, R. Rouas, G. Raicevic et al., "Mesenchymal stromal cells promote or suppress the proliferation of T lymphocytes from cord blood and peripheral blood: the importance of low cell ratio and role of interleukin-6," Cytotherapy, vol. 11, no. 5, pp. 570-583, 2009.

[46] K. Akiyama, C. Chen, D. D. Wang et al., "Mesenchymalstem-cell-induced immunoregulation involves FAS-ligand-/ FAS-mediated T cell apoptosis," Cell Stem Cell, vol. 10, no. 5, pp. 544-555, 2012.

[47] J. D. Glenn and K. A. Whartenby, "Mesenchymal stem cells: emerging mechanisms of immunomodulation and therapy," World Journal of Stem Cells, vol. 6, no. 5, pp. 526-539, 2014.

[48] T. Hato and P. C. Dagher, "How the innate immune system senses trouble and causes trouble," Clinical Journal of the American Society of Nephrology, vol. 10, no. 8, pp. 14591469, 2015.

[49] S. Jeyaseelan, H. W. Chu, S. K. Young, M. W. Freeman, and G. S. Worthen, "Distinct roles of pattern recognition receptors CD14 and Toll-like receptor 4 in acute lung injury," Infection and Immunity, vol. 73, no. 3, pp. 1754-1763, 2005.

[50] M. S. Jin, S. E. Kim, J. Y. Heo et al., "Crystal structure of the TLR1-TLR2 heterodimer induced by binding of a tri-acylated lipopeptide," Cell, vol. 130, no. 6, pp. 1071-1082, 2007.

[51] N. W. J. Schroder, H. Heine, C. Alexander et al., "Lipopolysaccharide binding protein binds to triacylated and diacylated lipopeptides and mediates innate immune responses," Journal of Immunology, vol. 173, no. 4, pp. 2683-2691, 2004.

[52] T. J. Sellati, D. A. Bouis, R. L. Kitchens et al., "Treponema pallidum and Borrelia burgdorferi lipoproteins and synthetic lipopeptides activate monocytic cells via a CD14-dependent pathway distinct from that used by lipopolysaccharide," Journal of Immunology, vol. 160, no. 11, pp. 5455-5464, 1998.

[53] M. Manukyan, K. Triantafilou, M. Triantafilou et al., "Binding of lipopeptide to CD14 induces physical proximity of CD14, TLR2 and TLR1," European Journal of Immunology, vol. 35, no. 3, pp. 911-921, 2005.

[54] B. Opitz, N. W. J. Schröder, I. Spreitzer et al., "Toll-like receptor-2 mediates Treponema glycolipid and lipoteichoic acid-induced NF- $\kappa \mathrm{B}$ translocation," The Journal of Biological Chemistry, vol. 276, no. 25, pp. 22041-22047, 2001.

[55] L. Oliveira-Nascimento, P. Massari, and L. M. Wetzler, "The role of TLR2 in infection and immunity," Frontiers in Immunology, vol. 3, 2012.

[56] L. Jin and R. P. Darveau, "Soluble CD14 levels in gingival crevicular fluid of subjects with untreated adult periodontitis," Journal of Periodontology, vol. 72, no. 5, pp. 634-640, 2001.

[57] T. Raunio, M. Knuuttila, R. Karttunen, O. Vainio, and T. Tervonen, "Serum sCD14, polymorphism of CD14 260 and periodontal infection," Oral Diseases, vol. 15, no. 7, pp. 484-489, 2009.

[58] D. M. Isaza-Guzmán, D. Aristizábal-Cardona, M. C. MartínezPabón, H. Velásquez-Echeverri, and S. I. Tobón-Arroyave, "Estimation of sCD14 levels in saliva obtained from patients with various periodontal conditions," Oral Diseases, vol. 14, no. 5, pp. 450-456, 2008.

[59] E. A. Nicu, M. L. Laine, S. A. Morré, U. Van der Velden, and B. G. Loos, "Soluble CD14 in periodontitis," Innate Immunity, vol. 15, no. 2, pp. 121-128, 2009.

[60] W. Li, G. Ren, Y. Huang et al., "Mesenchymal stem cells: a double-edged sword in regulating immune responses," Cell Death and Differentiation, vol. 19, no. 9, pp. 1505-1513, 2012.

[61] D. Liu, J. Xu, O. Liu et al., "Mesenchymal stem cells derived from inflamed periodontal ligaments exhibit impaired immunomodulation," Journal of Clinical Periodontology, vol. 39, no. 12, pp. 1174-1182, 2012.

[62] H. N. Tang, Y. Xia, Y. Yu, R. X. Wu, L. N. Gao, and F. M. Chen, "Stem cells derived from 'inflamed' and healthy periodontal ligament tissues and their sheet functionalities: a patientmatched comparison," Journal of Clinical Periodontology, vol. 43, no. 1, pp. 72-84, 2016. 
[63] S. Akashi, S. I. Saitoh, Y. Wakabayashi et al., "Lipopolysaccharide interaction with cell surface Toll-like receptor 4-MD-2," The Journal of Experimental Medicine, vol. 198, no. 7, pp. 1035-1042, 2003.

[64] D. Gao and W. Li, "Structures and recognition modes of Toll-like receptors," Proteins: Structure, Function, and Bioinformatics, vol. 85, no. 1, pp. 3-9, 2017. 


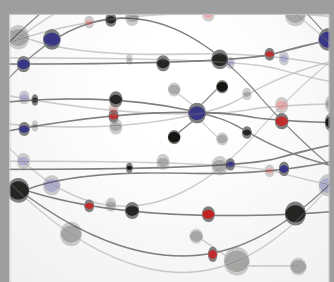

The Scientific World Journal
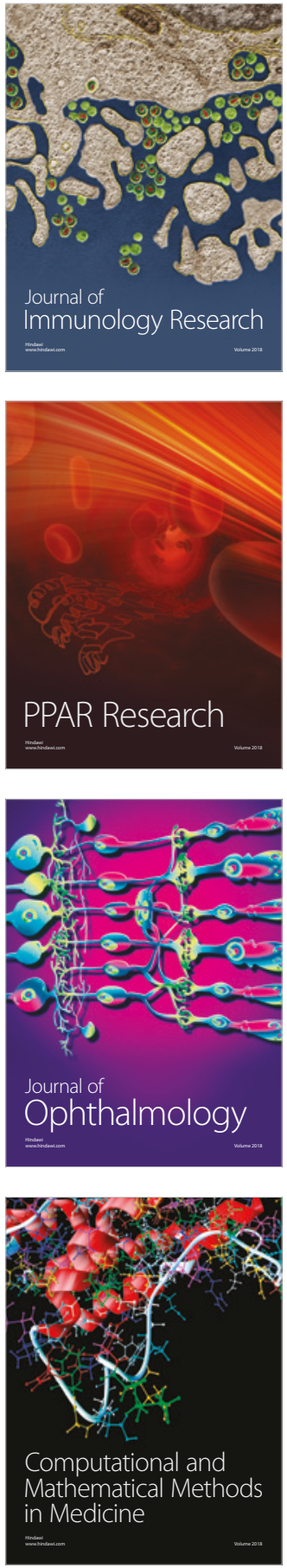

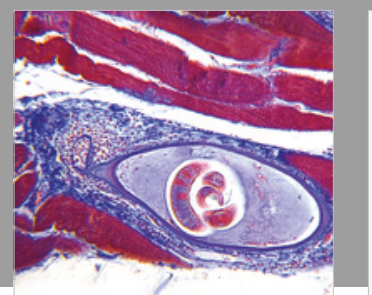

Gastroenterology Research and Practice

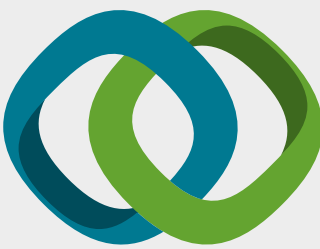

\section{Hindawi}

Submit your manuscripts at

www.hindawi.com
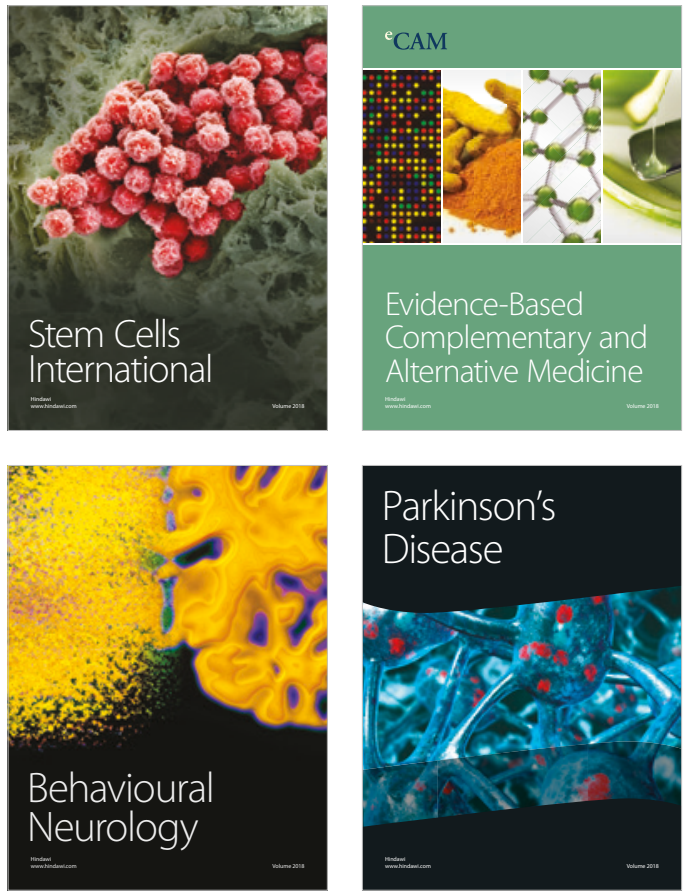

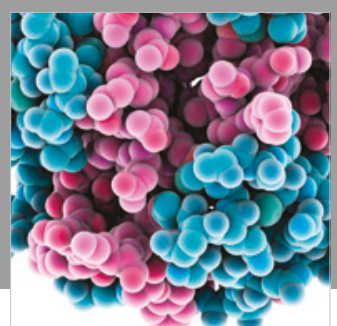

ournal of

Diabetes Research

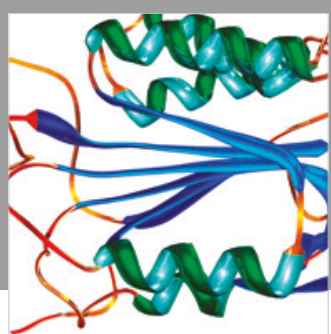

Disease Markers
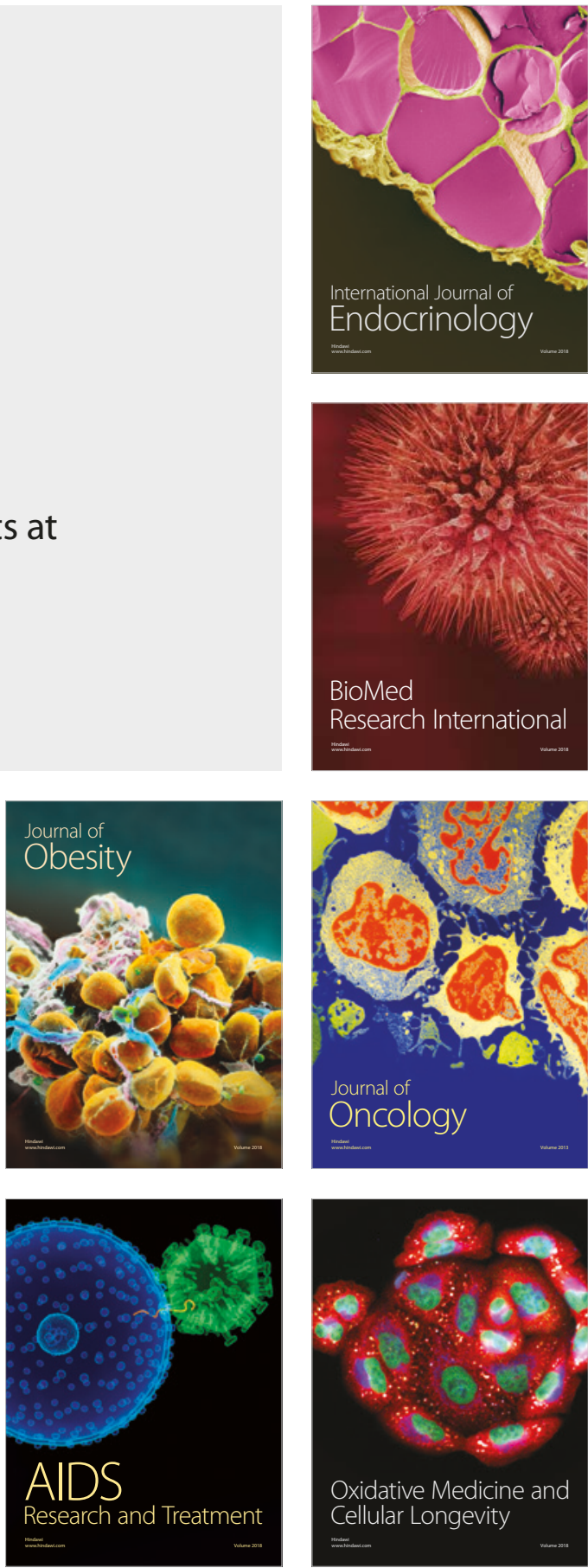